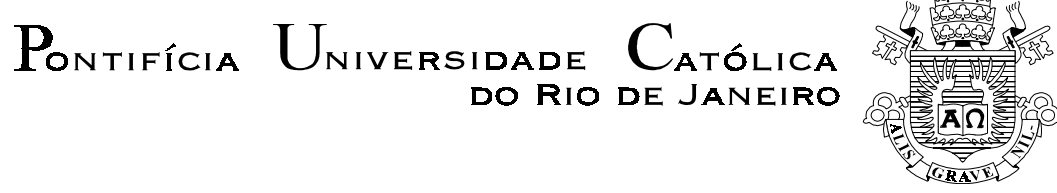

Maria Aparecida Cesar Amorim

\title{
O processo ensino-aprendizagem do português como segunda língua para surdos: os elementos conectores conjuntivos
}

Tese apresentada ao Programa de Pós-Graduação em Letras do Departamento de Letras da PUC-Rio como parte dos requisitos parciais para a obtenção do título de Doutor em Letras

Orientadora: Rosa Marina de Brito Meyer 


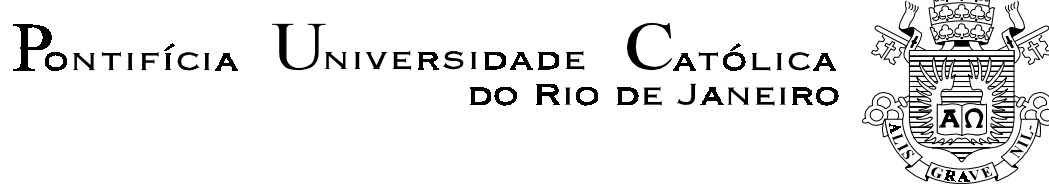

Maria Aparecida Cesar Amorim

O processo ensino-aprendizagem do português como segunda língua para surdos: os elementos conectores conjuntivos

Tese apresentada como requisito parcial para obtenção do grau de Doutor pelo programa de Pós-Graduação em Letras do Departamento de Letras do Centro de Teologia e Ciências Humanas da PUC-Rio. Aprovada pela Comissão Examinadora abaixo assinada.

Profa. Dra. Rosa Marina de Brito Meyer

Orientadora

Departamento de Letras - PUC-Rio

Profa. Dra. Eneida do Rêgo Monteiro Bomfim Departamento de Letras - PUC-Rio

Profa. Dra. Maria Carmelita Pádua Dias Departamento de Letras - PUC-Rio

Profa. Dra. Ronice Müller de Quadros UFSC

Profa. Dra. Virgínia Beatriz Baesse Abrahão

UFES

Prof. Dr. Jürgen Heye Coordenador Setorial do Centro de Teologia e Ciências Humanas

Rio de Janeiro, 15 de março de 2004 
Todos os direitos reservados. É proibida a reprodução total ou parcial do trabalho sem autorização da universidade, da autora e da orientadora.

\section{Maria Aparecida Cesar Amorim}

Graduou-se em Letras - Língua Portuguesa e literatura na UFJF (Universidade Federal de Juiz de Fora) em 1993 e, em 1994, em Língua Francesa e literatura. Em 1995, bacharelouse em Tradução: Língua Francesa, também pela UFJF. Cursou, em 1998, especialização em Formação de professores de português para estrangeiros pela Puc-Rio (Pontifícia Universidade Católica do Rio de Janeiro) e, em 1999, obteve o título de Mestre em Letras. Sua área de concentração é a Lingüística, com ênfase no processo ensino/aprendizagem do português do Brasil como segunda língua para estrangeiros e/ou para surdos.

Ficha Catalográfica

Amorim, Maria Aparecida Cesar

O processo ensino-aprendizagem do português como segunda língua para surdos: os elementos conectores conjuntivos / Maria Aparecida Cesar Amorim; orientadora: Rosa Marina de Brito Meyer. Rio de Janeiro: PUC-Rio, Departamento de Letras, 2004.

155 f. ; $30 \mathrm{~cm}$

Tese (doutorado) - Pontifícia Universidade Católica do Rio de Janeiro, Departamento de Letras.

Inclui referências bibliográficas

1. Letras - Teses. 2. Língua Portuguesa - Estudo e ensino. 3. Surdos - Educação. 4. Língua portuguesa Conectivos. 5. Segunda língua. I Meyer, Rosa Marina de Brito. II. Pontifícia Universidade Católica do Rio de Janeiro. Departamento de Letras. III. Título.

CDD: 400 
Aos meus sobrinhos Caroline (15 anos), Raphael (12 anos), Vicente (06 anos), César (05 anos) e Caio (04 anos), para que saibam que o conhecimento é o verdadeiro tesouro de nossas vidas. 


\section{Agradecimentos}

A Deus, meu Pai e a Jesus, meu Irmão.

À minha orientadora Prof ${ }^{a}$ Rosa Marina de Brito Meyer pelo estímulo e carinho para a realização deste trabalho, principalmente nos momentos mais difíceis.

À CAPES e ao CNPq, pelos auxílios concedidos, sem os quais este trabalho não poderia ter sido realizado.

Aos meus amigos que, numa corrente de amor, enviaram-me vibrações de energia, que me colocaram de pé quando as forças pareciam desvanecer-se.

À minha mãe pelo carinho de todas as horas.

Aos informantes surdos que colaboraram com esta pesquisa, com os quais aprendi muito mais do que eles acreditavam que eu tivesse para ensinar-lhes.

Aos professores e funcionários do Centro Educacional Pilar Velazquez pelo apoio para a realização deste trabalho.

Aos professores que participaram da Comissão examinadora.

A todos os professores e funcionários do Departamento pelas grandes lições e pelo apoio administrativo imprescindíveis para a feitura deste trabalho.

A todos os familiares pelo incentivo. 


\section{Resumo}

Amorim, Maria Aparecida Cesar; Meyer, Rosa Marina de Brito. O processo ensino-aprendizagem do português como segunda língua para surdos: os elementos conectores conjuntivos. Rio de Janeiro, 2004.155p. Tese de Doutorado. Departamento de Letras, Pontifícia Universidade Católica do Rio de Janeiro.

Esta pesquisa se propõe a analisar o conhecimento e emprego dos elementos conectores conjuntivos como, embora, mas e porque, por indivíduos surdos, considerando a LIBRAS - Língua Brasileira de Sinais - como a primeira língua destes, numa abordagem de ensino-aprendizagem do português como segunda língua. A partir das contribuições do Funcionalismo e da Semântica argumentativa, parte-se da aplicação de testes em informantes surdos, adolescentes e adultos, alunos/as de uma escola da rede particular de ensino da cidade do Rio de Janeiro, matriculados da $5^{\mathrm{a}}$ à $8^{\mathrm{a}}$ séries do ensino fundamental e que, nesta pesquisa, demonstram seu desempenho no emprego destes elementos conectores na modalidade escrita do português. Através dos resultados dos testes, verificou-se que a competência dos surdos no emprego dos elementos conectores conjuntivos está relacionada com fatores lingüísticos, tais como questões lexicais, sintáticas e semântico-textuais; e com fatores extralingüísticos, como nível de escolaridade, grau de surdez, faixa etária, grau de proficiência em LIBRAS e em português e tipo de teste aplicado. Constatou-se que os informantes que têm conhecimento da LIBRAS apresentam melhor desempenho em português. Destaca-se, por fim, a importância de reflexões em torno dessa temática para as linhas de pesquisa que discutem questões ligadas ao processo ensino-aprendizagem do português como segunda língua para surdos, bem como para a implementação de ações em torno das mudanças das metodologias vigentes no Brasil.

\section{Palavras-chave}

Português L2; surdez; funcionalismo; coesão; conectivos; como, embora, mas, porque 


\section{Abstract}

Amorim, Maria Aparecida Cesar; Meyer, Rosa Marina de Brito (Advisor). The Portuguese as a second language learning-teaching process for deaf people: the conjunctive connectors. Rio de Janeiro, 2004, 155p. Thesis - Departamento de Letras, Pontifícia Universidade Católica do Rio de Janeiro.

This research aims at analyzing the knowledge and use of the conjunctive connectors as, although, but and because by deaf people, considering LIBRAS Brazilian sign language - as their first language, in a Portuguese as a second language (L2) teaching-learning approach . Based on the functionalism model and on the argumentative semantics, it starts testing adolescent and adult deaf informants, students of some private schools in Rio de Janeiro, from the the $5^{\text {th }}$ to the $8^{\text {th }}$ grade, who demonstrate their performance in the usage of these connectors in the written form of the Portuguese language. Through the tests results we could verify that their competence in the use of conjunctive connectors elements relates to linguistic facts, such as lexical, syntactic and textual-semantic issues, and to extralinguistic facts, such as school level, deafness level, age, proficiency level at LIBRAS and Portuguese language, and also to the kind of test applied. It has been noticed that the informants who know LIBRAS have a better performance in Portuguese. Eventually, it is highlighted the importance of reflections on this theme to researches on the Portuguese teaching-learning process as a second language for the deaf, as well as to the implementation of actions concerning changes in the current Brazilian methodologies.

\section{Keywords}

Portuguese L2; deafness; functionalism; cohesion; connectives; as, although, but, because. 


\section{Sumário}

1. Introdução 14

1.1. Tema/problema 15

1.2. Objetivos 21

1.2.1. Objetivo geral 21

1.2.2. Objetivos específicos 22

1.3. Hipóteses 22

1.4. Divisão do trabalho 23

2. O ensino de português como segunda língua para ouvintes e surdos 25

2.1. O ensino de português como segunda língua para estrangeiros ouvintes 25

2.2. O ensino de português como segunda língua (L2) para surdos $\quad 27$

2.3. A conjunção vista sob o ângulo do português e da LIBRAS 30

2.4. O ensino de português como L2 e o ensino de LIBRAS no Centro Educacional Pilar Velazquez 31

2.4.1. Histórico do Centro Educacional Pilar Velazquez 32

2.4.2. Principais objetivos pedagógicos do Centro Educacional Pilar Velazquez

3. Revisão bibliográfica, pressupostos teóricos e procedimentos metodológicos $\quad 37$

3.1. Revisão bibliográfica 37

3.1.1. A abordagem da tradição gramatical 37

3.1.1.1. Os conceitos de conjunção 37

3.2. A visão da Pragmática 40

3.2.1. Conceitos de coesão $\quad 40$

3.3. Pressupostos teóricos 41

3.3.1. O Funcionalismo 41

3.3.2. Os elementos conectores conjuntivos e a Semântica Argumentativa 
3.4. Procedimentos metodológicos

3.4.1. Da caracterização da pesquisa 54

3.4.2. Da aplicação do questionário, entrevista e da observação dos dados cadastrais

3.4.3. A coleta de dados 56

3.4.4. O Corpus 56

3.4.5. Dos informantes 56

3.4.6. Dos testes 63

3.4.6.1. Das condições de aplicação 63

3.4.6.2. Da correção 65

3.4.6.3. Amostra dos tipos de teste aplicados 67

4. Análise dos dados $\quad 70$

4.1. Tabelas dos testes, conforme exposto em 3.4.6.2 70

4.2. Análise dos resultados do emprego dos elementos conectores conjuntivos $\quad 94$

4.2.1. Fatores lingüísticos $\quad 95$

4.2.1.1. Questões lexicais 95

4.2.1.2. Questões sintáticas 96

4.2.1.3. Questões semântico-textuais 98

4.2.2. Fatores extralingüísticos 102

4.2.2.1. Nível de escolaridade 102

4.2.2.2. Grau de surdez 106

4.2.2.2.1. Informantes com surdez profunda 107

4.2.2.2.2. Informantes com surdez severa 108

4.2.2.2.3. Informantes com surdez severa e profunda 109

4.2.2.2.4. Informantes com surdez não comprovada 110

4.2.2.3. Faixa etária 111

4.2.2.4.Grau de proficiência em LIBRAS e em português 116

4.2.2.5. Segundo o tipo de teste aplicado 118

4.3. Interpretação dos dados de acordo com os fatores extralingüísticos: nível de escolaridade, faixa etária, grau de surdez, grau de proficiência em LIBRAS e em português; e tipo de teste 
4.3.1. Tabela 41 - Resultado das adequações, inadequações e respostas desviantes por nível de escolaridade

4.3.2. Tabela 42 - Resultado das adequações, inadequações e respostas desviantes por faixa etária

125

4.3.2.1. Tabela 42a - Resultado das adequações, inadequações e respostas desviantes por cada faixa etária

4.3.2.2. Tabela 42b - Resultado das adequações, inadequações e respostas desviantes por grupo de faixa etária

126

4.3.3. Tabela 43 - Resultado das adequações, inadequações e respostas desviantes por grau de surdez

4.3.4. Tabela 44 - Resultado das adequações, inadequações e respostas desviantes de acordo com o grau de proficiência em LIBRAS e em português

128

4.3.4.1. Tabela 44a - Resultado das adequações, inadequações e respostas desviantes de acordo com o grau de proficiência em LIBRAS

129

4.3.4.2. Tabela 44b - Resultado das adequações, inadequações e respostas desviantes de acordo com o grau de proficiência em português

130

4.3.5. Tabela 45 - Resultado das adequações, inadequações e respostas desviantes de acordo com o tipo de teste aplicado

132

4.4. Considerações parciais

133

5. Conclusão

6. Referências bibliográficas

Anexos 


\section{Lista de tabelas}

Tabela 1. Resultado do teste $01-5^{\mathrm{a}}$ série 72

Tabela 2. Resultado do teste 02 - $5^{\mathrm{a}}$ série 72

Tabela 3. Resultado do teste 03 - $5^{\text {a }}$ série 73

Tabela 4. Resultado do teste $04-5^{\text {a }}$ série 73

Tabela 5. Resultado do teste $05-5^{\text {a }}$ série 74

Tabela 6. Resultado do teste $01-6^{\mathrm{a}}$ série $\quad 74$

Tabela 7. Resultado do teste $02-6^{\mathrm{a}}$ série 75

Tabela 8. Resultado do teste 03 - $6^{\text {a }}$ série 75

Tabela 9. Resultado do teste $04-6^{\text {a }}$ série 75

Tabela 10. Resultado do teste 05 - $6^{\text {a }}$ série 76

Tabela 11. Resultado do teste $01-7^{\mathrm{a}}$ série 76

Tabela 12. Resultado do teste 02 - $7^{\text {a }}$ série 76

Tabela 13. Resultado do teste $03-7^{\text {a }}$ série $\quad 77$

Tabela 14. Resultado do teste $04-7^{a}$ série $\quad 77$

Tabela 15. Resultado do teste $05-7^{\text {a }}$ série $\quad 77$

Tabela 16. Resultado do teste 01 - $8^{\text {a }}$ série 78

Tabela 17. Resultado do teste $02-8^{a}$ série 78

Tabela 18. Resultado do teste $03-8^{\mathrm{a}}$ série 78

Tabela 19. Resultado do teste 04 - $8^{\text {a }}$ série 79

Tabela 20. Resultado do teste $05-8^{a}$ série 79

Tabela 21. Resultado do teste $01-5^{\mathrm{a}}$ série 80

Tabela 22. Resultado do teste $01-6^{a}$ série 80

Tabela 23. Resultado do teste $01-7^{\text {a }}$ série 81

Tabela 24. Resultado do teste $01-8^{\mathrm{a}}$ série 81

Tabela 25. Resultado do teste 02 - $5^{\text {a }}$ série 81

Tabela 26. Resultado do teste 02 - $6^{a}$ série 82

Tabela 27. Resultado do teste 02 - $7^{\text {a }}$ série 82

Tabela 28. Resultado do teste 02 - $8^{a}$ série 82

Tabela 29. Resultado do teste 03 - $5^{\text {a }}$ série 83

Tabela 30. Resultado do teste 03 - $6^{\mathrm{a}}$ série 83

Tabela 31. Resultado do teste 03 - $7^{\text {a }}$ série 84 
Tabela 32. Resultado do teste $03-8^{a}$ série 84

Tabela 33. Resultado do teste 04 - $5^{\mathrm{a}}$ série 84

Tabela 34. Resultado do teste $04-6^{a}$ série 85

Tabela 35. Resultado do teste $04-7^{\mathrm{a}}$ série 85

Tabela 36. Resultado do teste $04-8^{\mathrm{a}}$ série 85

Tabela 37. Resultado do teste $05-5^{\mathrm{a}}$ série 86

Tabela 38. Resultado do teste $05-6^{\mathrm{a}}$ série 86

Tabela 39. Resultado do teste $05-7^{\text {a }}$ série 86

Tabela 40. Resultado do teste $05-8^{\text {a }}$ série 87

Tabela 41. Resultado das adequações, inadequações e respostas desviantes por nível de escolaridade $\quad 124$

Tabela 42. Resultado das adequações, inadequações e respostas desviantes por faixa etária

Tabela 43. Resultado das adequações, inadequações e respostas desviantes por grau de surdez

Tabela 44. Resultado das adequações, inadequações e respostas desviantes de acordo com o grau de proficiência em LIBRAS e em português

Tabela 45. Resultado das adequações, inadequações e respostas desviantes de acordo com o tipo de teste 
No caso de crianças surdas, uma postura de educação com bilingüismo, admitindo a língua de sinais como primeira língua e a língua oralauditiva como segunda, garantirá uma aquisição natural, atendendo ao desenvolvimento lingüístico e cognitivo normal da criança e permitindo a aquisição, subseqüente, da segunda língua, com maior facilidade, uma vez que este indivíduo já domina um instrumento de comunicação eficaz para si mesmo e para comunicar-se com o meio que o cerca, mesmo que haja poucos interlocutores da lingua que domina. [...] A adoção de uma filosofia educacional consistente, que de conta de um projeto educacional para surdos, não pode ignorar a interlocução constante. Não há apenas surdos a ensinar, mas ouvintes e surdos a aprender como educar surdos.

Eulália Fernandes, Linguagem e surdez 